\title{
Unusual death due to a bleeding from a varicose vein: a case report
}

\author{
Kleio Fragkouli, Antigoni Mitselou, Vassiliki A Boumba, George Siozios, George TVougiouklakis \\ and Theodore Vougiouklakis
}

\begin{abstract}
Background: Varicose veins are a common entity presenting a worldwide distribution. Although they are usually benign, sometimes are proved to be a threatening condition. Massive hemorrhage is an unusual complication of this common venous pathology that demands immediate medical intervention.

Case presentation: We present a case of a 66-year-old woman found dead in her house surrounded by a large quantity of blood. Autopsy revealed a $7 \mathrm{~mm}$ ulcer on the internal surface of the left lower leg communicating with a varicose vein, signs of exsanguinations and liver cirrhosis. Toxicological analysis was negative.

Conclusion: Massive hemorrhage from a ruptured varicosity is a severe medical emergency. Awareness of the risk of massive hemorrhage may provoke preventive treatment to be undertaken so as terminal loss of consciousness and a subsequent unattended death to be averted.
\end{abstract}

Keywords: Varicose vein rupture, Massive hemorrhage, Autopsy, Medical emergency

\section{Background}

Varicose veins are a chronic clinical condition well known since antiquity and with a wide distribution [1]. According to a review of patients in Western countries, varicose veins affect one quarter to one third of all adults [2]. Although they are usually benign [3], severe varicosities may lead to major complications including edema, dermatitis, ulceration and severe bleeding [4]. The latter can be exacerbated when other factors - such as anticoagulant medications, alcohol, sedatives - contribute [5]. Cases where significant hemorrhage takes place may simulate arterial bleeding and represent medical emergencies and may lead to death if not treated immediately [6]. Those cases may mimic violent deaths because of the usually abundant amount of blood found at the scene of death [7].

We present an autopsy case of a 66-year-old woman who died due to fatal varicose vein rupture in the context of liver cirrhosis.

\footnotetext{
*Correspondence: tvujuk@cc.uoi.gr

Department of Forensic Medicine and Toxicology, University of Ioannina, loannina, Greece
}

\section{Biomed Central}

(c) 2012 Fragkouli et al.; licensee BioMed Central Ltd. This is an Open Access article distributed under the terms of the Creative Commons Attribution License (http://creativecommons.org/licenses/by/2.0), which permits unrestricted use, distribution, and reproduction in any medium, provided the original work is properly cited.

\section{Case presentation}

A 66-year-old woman was found dead by a neighbor at her home, lying in a large quantity of blood. Multiple bloodsoaked tissues were found around her body (Figure 1). The examination of the rest of the house revealed smears and smaller blood pools. The woman was living alone and her medical history was unknown.

During autopsy, sparely developed livers were observed on the body. The skin of her left lower leg showed significant edema, brownish-red discoloration and induration, compatible with chronic venous insufficiency. On the internal surface of left lower leg a $7 \mathrm{~mm}$ cutaneous ulcer was situated (Figure 2A). On dissection, the surrounding skin was remarkably firm, the ulcer margin was reddish and folded, whereas the base of the ulcer was red and with evidence of continuation with a superficial vein. No obvious traumatic lesions were observed.

Remarkable findings on internal examination included significant pallor of all the organs, subendocardial hemorrhages, a small yellowish, nodular and firm liver and an enlarged and congested spleen.

Histology revealed pulmonary edema and liver cirrhosis. Additionally, a defect in the epidermis with signs of continuity with a superficial vein was observed. The 


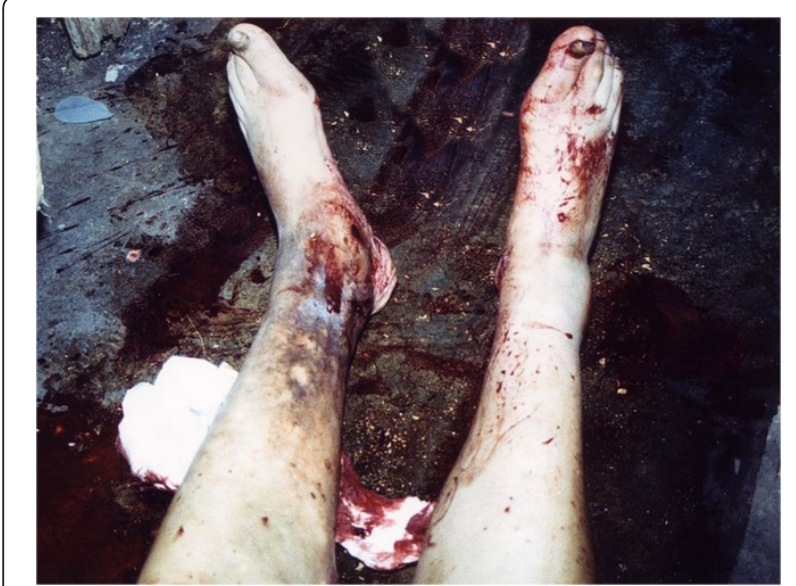

Figure 1 The scene of death. Victim's low extremities surrounded by high quantity of blood and blood-soaked tissues.

ulcer margin was covered by epidermis that abutted above, within or under the few fibrinous exudates. The underlying dermis contained numerous small and medium-sized blood vessels, filled with red blood and surrounded by thick organized fibrous cuffs. The remainder dermis presented fibrosis and abundant macrophages, as well as focally extravasated red blood cells and perivascular deposits of hemosiderin, a sign of repeated past dermal micro-hemorrhages (Figure 2B).

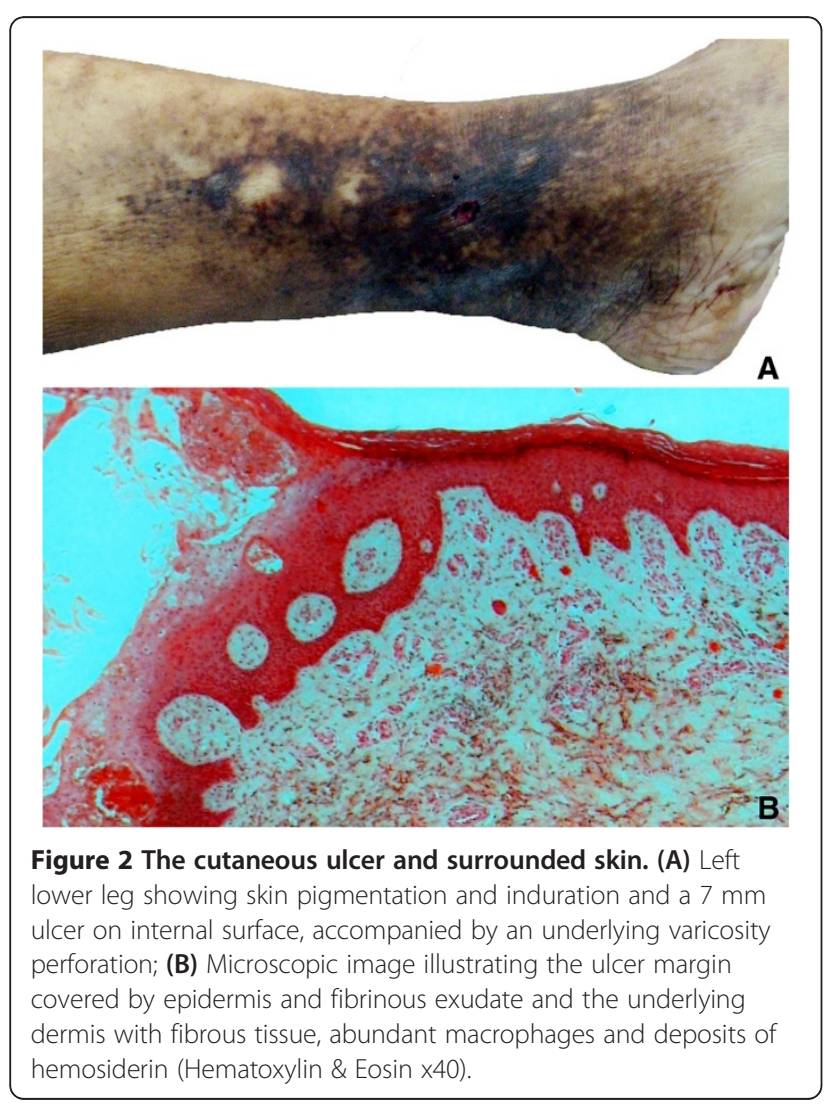

Toxicological analysis was negative.

Death was attributed to massive hemorrhage due to rupture of a varicose vein of the left lower leg.

\section{Discussion}

Death from fatal hemorrhage due to varicose vein rupture is a well described phenomenon with a recognized representation in the literature [4-15]. Nevertheless, the incidence of this pathology as a cause of death presents a wide variety. Reported figures include a prevalence of 23 cases during a single year in England and Wales [8], and an incidence of $<1: 1000$ in another autopsy series [4]. A total number of 66 cases have been described in reports since the phenomenon was described for the first time in 1973 [4-15]. The youngest person dying of fatal varicosity rupture up to date has been reported to be a 29-year-old man who was found deceased in his store lying in abundant blood [15].

Two types of ulceration related to fatal hemorrhage have been described: the acute perforative type, which is a small lesion $(<5 \mathrm{~mm})$ with almost no skin involvement; and the chronic ulceration, being a large lesion (10-100 $\mathrm{mm}$ ) associated with skin pigmentation and induration and erosion into a superficial or deep vein of the leg [8]. In the present case, the ulcer was relatively small $(7 \mathrm{~mm})$ but there were also intense signs of longstanding venous insufficiency and stasis dermatitis, belonging finally in the chronic type. However, a combination with a minor trauma cannot be ruled out.

Characteristic features of deaths due to massive bleeding from a ruptured varicose vein have been mentioned. They include old age, social isolation, possible underlying medical conditions (e.g. restricted mobility, dementia), hemorrhage related to minor trauma, a rapid outcome and some associated features such as alcohol consumption or anticoagulant medications [4]. Another important risk factor is sclerotic changes of the vessel walls that may lead to spontaneous hemorrhage [13]. Additionally, predisposing factor to death has been reported to be a coexisting disease, such as ischemic heart disease [4]. Interestingly, in the case described herein, the presence of liver cirrhosis seems to have contributed to the fatal outcome. The chronic disturbance in the capacity of liver to produce the coagulant factors in the case of cirrhosis prevented the formation of a blood-clot to suppress the massive loss of blood, predisposing to significant hemorrhage and accelerating the death procedure.

In the cases of death due to varicosity rupture it is worth mentioning the victims' failure to give themselves the adequate immediate medical care, e.g. direct pressure application and elevation of the bleeding limb. The victim in the present case tried to give herself a first aid, as bloodstained tissues were found around her at the place of death, but the 
coexisting liver pathology (cirrhosis) seems to have exaggerated hemorrhage, something that quickly resulted in unconsciousness and hastened death. Such a hemorrhage is definitely a medical emergency and requires prompt treatment. However, the possible lack of training and obtaining the right information relevant to this pathology, as well as the false appreciation of the importance of bleeding due to mental disease or alcohol ingestion, are the main factors that no first aids are given [4].

\section{Conclusion}

Although varicose veins are a benign clinical pathology, they conceal the danger of rupture, especially if left untreated. The subsequent venous bleeding can be severely intensive and can quickly lead to a loss of consciousness and death. This case is remarkable from the forensic pathology point of view but also contains a preventive imperative. Awareness of the risk of massive hemorrhage may provoke preventive treatment to be undertaken. Therefore, therapists and general practitioners should bear in mind that whenever they treat a patient for varicose veins or any other pathology that might deteriorate varicosities, they should always consider the possibility of adverse interaction of the morbid entities leading to fatal bleeding of a varicose vein.

\section{Consent}

Written informed consent was obtained from the patient daughter (next of kin since the patient is dead) for publication of this case report and any accompanying images. A copy of the written consent is available for review by the Editor-in-Chief of this journal.

\section{Competing interests}

The authors declare that they have no competing interests.

\section{Authors' contributions}

KF wrote the manuscript, performed the literature search and contributed to autopsy. AM performed the histological examination and provided the micro-photograph. VB performed the toxicological analysis. GS and GTV contributed to autopsy and have been involved in drafting the manuscript. TV performed the autopsy and revised the manuscript. All authors read and approved the final manuscript.

Received: 31 May 2012 Accepted: 31 August 2012

Published: 5 September 2012

\section{References}

1. Beaglehole R: Epidemiology of varicose veins. World J Surg 1986, 10:898-902.

2. Bartholomew JR, King T, Sahgal A, Vidimos AT: Varicose veins: newer, better treatments available. Cleve Clin J Med 2005, 72(4):312-328.

3. Beebe-Dimmer JL, Pfeifer JR, Engle JS, Schottenfeld D: The epidemiology of chronic venous insufficiency and varicose veins. Ann Epidemiol 2005, 15:175-184.

4. Byard RW, Gilbert JD: The incidence and characteristic features of fatal hemorrhage due to ruptured varicose veins. A 10-year autopsy study. Am J Forensic Med Pathol 2007, 28:299-302.

5. Hejna P: A case of fatal spontaneous varicose vein rupture - an example of incorrect first aid. J Forensic Sci 2009, 54:1146-1148.
6. Sauvageau A, Scellenberg M, Racette S, Julien F: Bloodstain pattern analysis in a case of fatal varicose vein rupture. Am J Forensic Med Pathol 2007, 28:35-37.

7. Byard RW, Veldhoen D, Manock C, Gilbert JD: Blood stain pattern interpretation in cases of fatal haemorrhage from ruptured varicose veins. J Forensic Leg Med 2007, 14:155-158.

8. Evans GA, Seal RME, Evans DMD, Craven JL: Spontaneous fatal haemorrhage caused by varicose veins. Lancet 1973, 1:1359-1361.

9. Racette S, Sauvageau A: Unusual sudden death. Two case reports of hemorrhage by varicose veins. Am J Forensic Med Pathol 2005, 26:294-296.

10. Cittadini F, Albertacci G, Pascali VL: Unattended fatal hemorrhage caused by spontaneous rupture of a varicose vein. Am J Forensic Med Pathol 2008, 29:92.

11. Morrow PL, Hardin NJ, Karn CM, Beloin R, McDowell RW: Fatal hemorrhage caused by varicose veins. Am J Forensic Med Pathol 1994, 15:100-104.

12. Püschel K: Plötzlicher Tod im Erwachsenenalter (Sudden death in adulthood). In Handbuch gerichtliche Medizin. Volume 1st edition. Edited by Brinkmann B, Madea B. Berlin, Heidelberg, New York: Springer; 2004:1041.

13. Doberentz E, Hagemeier L, Veit C, Madea B: Unattended fatal haemorrhage due to spontaneous peripheral varicose vein rupture-two case reports. Forensic Sci Int 2011, 206(1-3):e12-e16.

14. Nikolić S, Živković V: [Fatal exsanguination due to ruptured vericose vein of the lower leg: case report]. Srp Arh Celok Lek 2011, 139:819-823.

15. Ampanozi G, Preiss U, Hatch GM, Zech WD, Ketterer T, Bolliger S, Thali MJ, Ruder TD: Fatal lower extremity varicose vein rupture. Leg Med 2011 13:87-90.

\section{doi:10.1186/1756-0500-5-488}

Cite this article as: Fragkouli et al: Unusual death due to a bleeding from a varicose vein: a case report. BMC Research Notes 2012 5:488.

\section{Submit your next manuscript to BioMed Central and take full advantage of:}

- Convenient online submission

- Thorough peer review

- No space constraints or color figure charges

- Immediate publication on acceptance

- Inclusion in PubMed, CAS, Scopus and Google Scholar

- Research which is freely available for redistribution 